\title{
Binocular coordination and reading performance during smartphone reading in intermittent exotropia
}

This article was published in the following Dove Press journal:

Clinical Ophthalmology

\author{
Masakazu Hirota' \\ Hiroyuki Kanda' \\ Takao Endo 2 \\ Takeshi Morimoto' \\ Tomomitsu Miyoshi ${ }^{3}$ \\ Takashi Fujikado' \\ 'Department of Applied Visual \\ Science, Osaka University Graduate \\ School of Medicine, Suita, Osaka, \\ Japan; ${ }^{2}$ Department of Ophthalmology, \\ Osaka University Graduate School \\ of Medicine, Izumi, Osaka, Japan; \\ ${ }^{3}$ Department of Integrative Physiology, \\ Osaka University Graduate School of \\ Medicine, Suita, Osaka, Japan
}

Correspondence: Takashi Fujikado Department of Applied Visual Science, Osaka University Graduate School of Medicine, 2-2 Yamadaoka, Suita-shi,

Osaka 565-087I, Japan

$\mathrm{Tel}+8 \mathrm{I} 668793943$

Fax +8I 668793948

Email fujikado@ophthal.med.osaka-u.ac.jp
Purpose: This study aimed to evaluate binocular coordination using video-oculography during smartphone reading in patients with intermittent exotropia compared to individuals with normal vision.

Patients and methods: Eleven youth and adult patients with intermittent exotropia

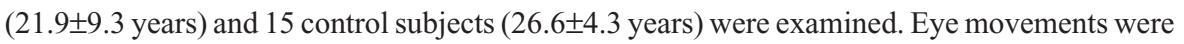
recorded during smartphone reading at 50,30 , and $20 \mathrm{~cm}$ using video-oculography. The loss of binocular coordination was tentatively defined as a horizontal disparity greater than $2^{\circ}$. The proportion of monocular viewing was the percentage of time for which binocularity was lost during smartphone reading. The proportion of monocular viewing, the reading speed, and the correlation between proportion of monocular viewing and reading speed were analyzed.

Results: The proportion of monocular viewing during smartphone reading was significantly higher in the intermittent exotropia group than in the control group $(P<0.001)$. It was significantly more frequent at $20 \mathrm{~cm}$ than at $50 \mathrm{~cm}$ in the intermittent exotropia group $(P<0.05)$. The reading speed was significantly negatively correlated with the proportion of monocular viewing at 30 and $20 \mathrm{~cm}$ in the intermittent exotropia group $(P<0.05)$.

Conclusion: A significant increase in the proportion of monocular viewing in the intermittent exotropia group suggests that an appropriate viewing distance should be advised so that users can maintain binocular coordination when viewing a smartphone.

Keywords: eye movement, smartphone reading, video-oculography, intermittent exotropia

\section{Introduction}

Smartphones are widely used because they permit easy access to the Internet. ${ }^{1}$ More than $50 \%$ of youth in developed countries such as USA and Japan use smartphones daily to access social networking services. ${ }^{2,3}$ Although smartphones are useful for communication and the proportion of people using them daily continues to increase each year, ${ }^{4}$ health problems are also noted with their use, such as acute acquired comitant esotropia. ${ }^{5}$

Intermittent exotropia $(\mathrm{X}(\mathrm{T}))$ is the most common form of childhood-onset exotropia. ${ }^{6-8}$ It is characterized by exodeviation, prolonged near point of convergence, and low fusional convergence at close distances. ${ }^{9,10}$ The clinical management of X(T) has been based on the angle of deviation at a distance and at proximity using the prism cover test. ${ }^{11}$ Typically, this test is performed with the individual focusing on an accommodative target at the static eye position in Listing's law. ${ }^{12}$ However, static eye position is not a natural visual state, and there is a possibility that functional $\mathrm{X}(\mathrm{T})$ is underestimated, such as with the proportion of monocular viewing. 
In this study, we measured binocular eye movement during smartphone reading in patients with $\mathrm{X}(\mathrm{T})$ using videooculography (VOG) and investigated whether binocular coordination was maintained during reading.

\section{Patients and methods Subjects}

The study cohort comprised 11 patients diagnosed with $\mathrm{X}(\mathrm{T})$ (age, mean $\pm \mathrm{SD}, 21.9 \pm 9.3$ years; range, $13-40$ years) recruited from the Department of Ophthalmology, Osaka University Hospital, Osaka, Japan.

Control subjects were 15 healthy young volunteers (age, 26.6 \pm 4.3 years; range, 21-35 years). All participants underwent complete ophthalmologic examinations that included visual acuity at a distance of $5.0 \mathrm{~m}$, stereo acuity (Titmus Stereo Tests; Stereo Optical Co, Inc, Chicago, IL, USA) at a distance of $40 \mathrm{~cm}$, and angle of deviation using the alternate prism cover test both near $(33 \mathrm{~cm})$ and distant $(5.0 \mathrm{~m})$. Stereo acuity was converted to logarithm of arcsecond $(\log \operatorname{arcsec})$.

The inclusion criteria were use of a smartphone every day and no diplopia or blurry vision during smartphone use. All participants confirmed daily smartphone use and reported no diplopia or blurry vision during smartphone use. Moreover, participants and their families confirmed that they had been using the smartphone at a distance of 20-30 cm. Participants were excluded if they could not maintain binocularity at $20 \mathrm{~cm}$ in the first eye position. The high-myopia participants and those with refractive error over $\pm 9.00 \mathrm{D}$ were also excluded.

Written informed consent was obtained from all participants after the nature and possible complications of the study were explained. Moreover, in cases wherein patients were younger than 18 years of age, a parent or legal guardian provided written informed consent. This investigation adhered to the tenets of the World Medical Association's Declaration of Helsinki. The experimental protocol and consent procedures were approved by the Institutional Review Board of Osaka University Medical School (approval number 14037-3).

\section{Eye movement recordings}

Eye movements were recorded during smartphone reading using the Tobii TX300 eye tracker (TX300; Tobii Technology Co, Ltd, Stockholm, Sweden). TX300 determines the eye position by detecting the corneal reflex created by near-infrared light and compensates for $15 \times 7$ " of freedom of head movement at $65 \mathrm{~cm}$. Additionally, the TX300 eye tracker was tolerant of reflection and/or minification effects until $-8.00 \mathrm{D}$ in our pilot study. The sampling rate was $120 \mathrm{~Hz}$, and the measurement angle was $\pm 35^{\circ}$ from the center of the monitor. TX300 permitted measurement at any fixation distance between 50 and $80 \mathrm{~cm}$, and the measurement error was in the range of $0.3^{\circ}-0.5^{\circ}$ (IQR) at $65 \mathrm{~cm}$.

All subjects underwent a calibration test under binocular conditions at each distance before the reading task because pupillary diameter in adult patients with $\mathrm{X}(\mathrm{T})$ significantly changed between monocular and binocular conditions. ${ }^{13}$ The pupillary diameter reportedly differed between monocular and binocular conditions, ${ }^{14}$ and the change in pupillary diameter affected the accuracy of VOG. ${ }^{15}$

During calibration, all participants were asked to fixate on five cross targets (visual angles of $0.23^{\circ}$ at $50 \mathrm{~cm}, 0.38^{\circ}$ at $30 \mathrm{~cm}$, and $0.57^{\circ}$ at $20 \mathrm{~cm}$ ) at the four corners and center of the smartphone screen (Figure 1). The center of the screen was defined as $0^{\circ}$ horizontal and vertical. The right and upper halves of the screen were defined as the positive side, while the left and lower halves were defined as the negative side.

After calibration, the examiner confirmed that the center of binocular gaze position in all subjects converged within the measurement error range of the TX300 using Tobii Studio software.

\section{Reading task}

The difficulty of the reading task was adjusted to a junior high school reading level and was performed using Amazon Kindle for Android (Amazon.com, Inc, Seattle, WA, USA; Figure 1A) to approximate normal daily smartphone use. The viewing distances were set at 50, 30, and $20 \mathrm{~cm} .{ }^{16,17}$ The Japanese translation of The Little Prince (by Antoine de Saint-Exupéry) was displayed on the smartphone screen (NEXUS5; LG Electronics Inc, Seoul, Korea; resolution, $1,920 \times 1,080$; screen illuminance, $300 \mathrm{~cd} / \mathrm{m}^{2}$ ).

The text comprised logographic kanji (Chinese characters) and syllabic kana characters vertically displayed in black on white. The font size of the text was 12 points, and the space between the lines was $0.25^{\circ}$ at $50 \mathrm{~cm}, 0.42^{\circ}$ at $30 \mathrm{~cm}$, and $0.63^{\circ}$ at $20 \mathrm{~cm}$. The length of a line was up to $97 \mathrm{~mm}$ $\left(11.1^{\circ}\right.$ at $50 \mathrm{~cm}, 17.9^{\circ}$ at $30 \mathrm{~cm}$, and $25.5^{\circ}$ at $\left.20 \mathrm{~cm}\right)$, with a maximum of 35 characters per line $(50 \mathrm{~cm}, 579$ characters; $30 \mathrm{~cm}, 808$ characters; and $20 \mathrm{~cm}, 687$ characters). The text size was not rescaled for target distance in order to replicate eye movements under situations close to everyday smartphone use.

All participants were seated in a well-lit room (600 lx) wearing fully corrective glasses. They were instructed to 

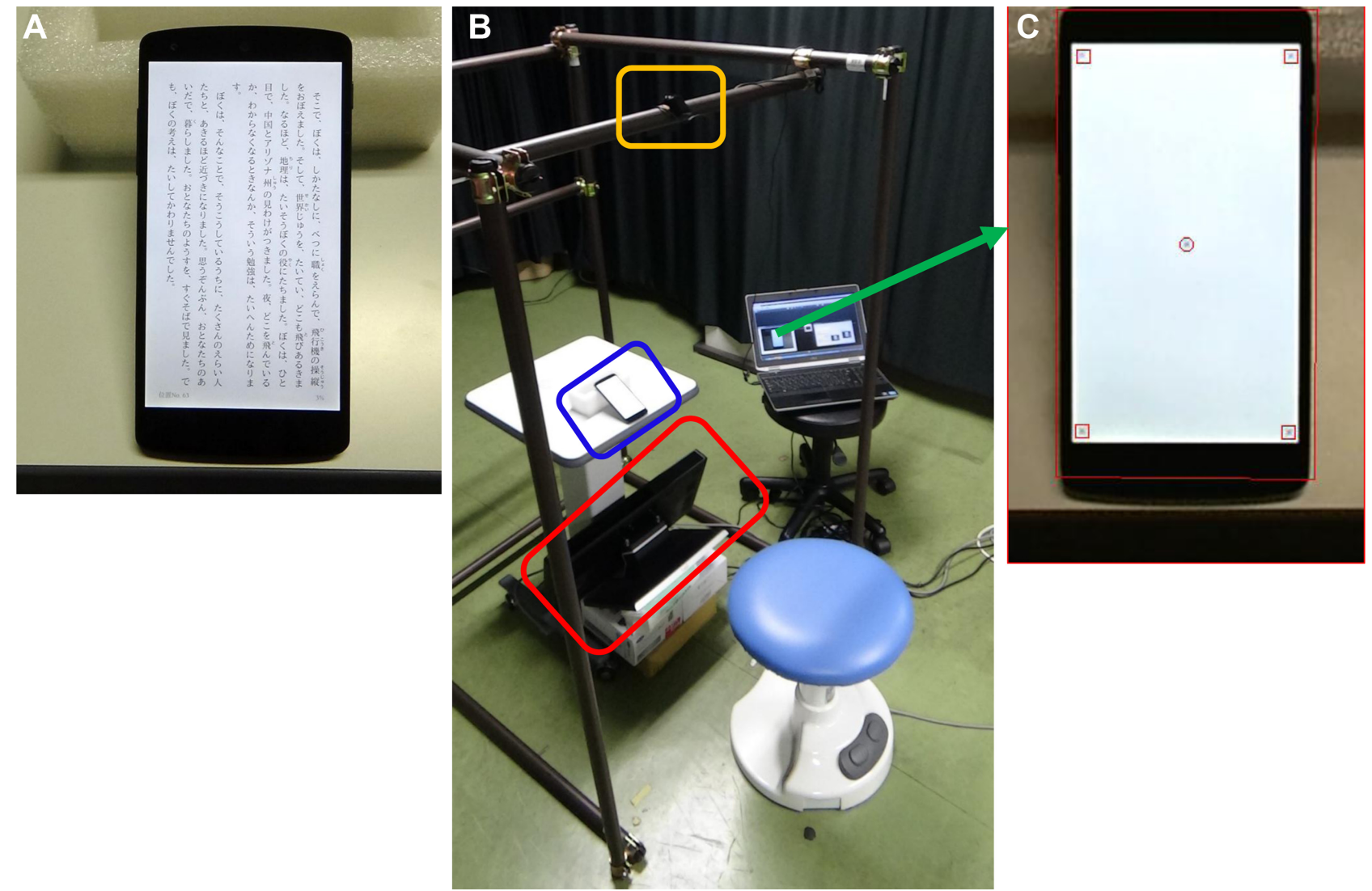

Figure I Experimental environment to evaluate binocular vision during smartphone reading.

Notes: The TX300 was set under an electric instrument table. An adjustable electric stool was used to ensure a distance of $65 \mathrm{~cm}$ from subjects' eyes. The smartphone was placed on the electric instrument table. A web camera used to observe whether the smartphone screen was set over the electric instrument table and linked with Tobii Studio eye tracking software. (A) Reading task. (B) Recording systems. Blue box: smartphone; red box: Tobii eye tracker TX300; yellow box: web camera. (C) Calibration screen.

read three pages of text silently, swiping the smartphone screen to turn pages at their own reading speed without head movement. The reading task was performed in order at distances of 50, 30, and $20 \mathrm{~cm}$. An examiner asked all participants if they were aware of diplopia or blurred vision at each distance of the smartphone in this experiment after reading at each distance.

\section{Experimental environment}

The TX300 was set under an electric instrument table (OT-450; Nidek Co, Ltd, Aichi, Japan). The distance between the TX300 and the subjects' eyes was set at $65 \mathrm{~cm}$ by adjusting an electric stool (DR-070; Takara Belmont Corp, Osaka, Japan). The smartphone was placed on the electric instrument table (Figure 1B and C). A web camera (C910, Logitech Corp, Vaud, Switzerland), for observation of the smartphone screen, was set over the electric instrument table and linked with Tobii Studio eye tracking software (Tobii Technology Co, Ltd, Stockholm, Sweden).

\section{Data collection}

All eye movement data were exported into an Excel file (Microsoft Co, Ltd, Redmond, WA, USA) using Tobii Studio software. Horizontal and vertical eye movements were analyzed, and saccade, fixation, and blinking were automatically identified using a velocity threshold identification (I-VT) filter with Tobii Studio software. An I-VT filter was used to classify eye movements based on the velocity of the directional shifts of the eye. Saccade was defined as a median value of three consecutive windows exceeding $30^{\circ} / \mathrm{s}$.

The horizontal and vertical fixation disparities (left eye right eye [deg]) during reading were calculated. A value of $0^{\circ}$ indicated that the two eyes aligned at the letter on the smartphone. Positive values represented crossed fixations (eso- or hyperfixation disparity); whereas negative values represented uncrossed fixations (exo- or hypofixation disparity).

Fixation disparity was a small vergence error in binocular vision. ${ }^{18}$ Previous studies commonly showed that the horizontal fixation disparity, measured by VOG, had a variance 
of $2^{\circ} \cdot{ }^{19,20}$ Therefore, monocular viewing was tentatively defined in the present study as a horizontal disparity greater than $2^{\circ}$. The proportion of monocular viewing was calculated using the following formula: monocular viewing time/total reading time.

Reading speed was a common legibility metric for evaluating reading performance. ${ }^{21}$ In this study, reading speed was evaluated by the number of characters per second (cps), including repagination by a screen swipe.

\section{Statistical analysis}

Differences in the proportion of monocular viewing, reading speed, and horizontal fixation disparity at each distance between and within the groups was determined using the Mann-Whitney $U$ test and Schéffe test. Correlation between reading speed and the proportion of monocular viewing was determined using single linear regression analysis for each distance.

IBM SPSS Statistics 24 software (IBM Corporation, Armonk, NY, USA) was used for all analyses. A $P$-value of $<0.05$ was considered statistically significant.

\section{Results \\ Demographics}

Table 1 summarizes that among the patients with $\mathrm{X}(\mathrm{T})$, the mean spherical equivalent (SE) refractive error of the right eye was $-4.6 \pm 2.3 \mathrm{D}$ (range, -0.25 to $-8.00 \mathrm{D}$ ), and the same for the left eye was $-4.4 \pm 2.3 \mathrm{D}$ (range, -0.25 to $-7.25 \mathrm{D}$ ). The best-corrected visual acuity (BCVA) was $\geq 20 / 20$ in all patients. The mean angle of deviation was $13.2 \pm 13.2$ prism D base in (PD-bi) (range, 2-50 PD-bi) at distance and 24.0 \pm 9.2 PD-bi (range, 12-45 PD-bi) near. The mean stereo acuity was $1.8 \pm 0.3 \log \operatorname{arcsec}$ (range, 1.60-2.60 log arcsec).
Table 2 summarizes that among the control subjects, the mean SE refractive error of the right eye was $-2.4 \pm 2.0 \mathrm{D}$ (range, +0.75 to $-5.50 \mathrm{D}$ ), and that for the left eye was $-2.5 \pm 1.9 \mathrm{D}$ (range, +0.50 to $-5.50 \mathrm{D}$ ). The BCVA was $\geq 20 / 20$ in all. The mean angle of deviation was $0.3 \pm 1.0$

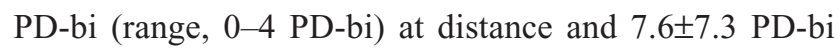
(range, 0-25 PD-bi) near. All healthy individuals had stereo acuity of $1.60 \log$ arcsec.

\section{Reading performance of $X(T)$ and control groups}

The proportion of monocular viewing by disruption of binocular coordination during smartphone reading was significantly higher in the $\mathrm{X}(\mathrm{T})$ group than in the control group $(50 \mathrm{~cm}$, mean \pm SD, $11.9 \% \pm 19.5 \%$ vs $0 \% ; 30 \mathrm{~cm}, 19.7 \% \pm 23.8 \%$ vs $0 \%$; and $20 \mathrm{~cm}, 41.0 \% \pm 29.4 \%$ vs $0 \% ; P<0.001$; Figures 2 and 3A, Table 3, Supplementary videos $\underline{\mathrm{S} 1}$ and $\underline{\mathrm{S} 2}$ ). Within the $X(T)$ group, the proportion of monocular viewing at $20 \mathrm{~cm}$ was significantly higher than that at $50 \mathrm{~cm}(P=0.03$; Figure $3 \mathrm{~A}$, Table 3), but it did not differ significantly within the control group (Figure 3A, Table 3). All patients reported no diplopia and/or blurred vision during smartphone reading.

Reading speed was significantly slower in the $\mathrm{X}(\mathrm{T})$ group than in the control group at 30 and $20 \mathrm{~cm}(50 \mathrm{~cm}, 6.3 \pm 0.8 \mathrm{cps}$ vs $7.2 \pm 1.8 \mathrm{cps}, P=0.50 ; 30 \mathrm{~cm}, 7.9 \pm 1.4 \mathrm{cps}$ vs $9.3 \pm 1.7 \mathrm{cps}$, $P=0.04$; and $20 \mathrm{~cm}, 7.4 \pm 1.1 \mathrm{cps}$ vs $9.4 \pm 2.0 \mathrm{cps}, P=0.01$; Figure $3 \mathrm{~B}$, Table 3 ). The reading speed was significantly slower at $50 \mathrm{~cm}$ than at $30 \mathrm{~cm}$ in both groups and was significantly slower at $50 \mathrm{~cm}$ than at $20 \mathrm{~cm}$ in the control group [X(T): 50 vs $30 \mathrm{~cm}, P=0.01$; Control: 50 vs $30 \mathrm{~cm}, P=0.01$; 50 vs $20 \mathrm{~cm}, P=0.01$; Figure 3B, Table 3].

The reading speed was significantly negatively correlated with the proportion of monocular viewing at 20 and $30 \mathrm{~cm}$

Table I Characteristics of patients in the intermittent exotropia group

\begin{tabular}{|c|c|c|c|c|c|c|}
\hline \multirow[t]{2}{*}{ Patient } & \multirow[t]{2}{*}{ Age (years) } & \multicolumn{2}{|c|}{ Spherical equivalent (D) } & \multicolumn{2}{|c|}{ APCT (PD-bi) } & \multirow{2}{*}{$\begin{array}{l}\text { Stereoacuity } \\
\text { (log arcsec) }\end{array}$} \\
\hline & & RE & LE & Near & Distance & \\
\hline $\mathrm{PI}$ & 19 & -6.75 & -6.75 & 20 & 2 & 1.7 \\
\hline P2 & 17 & -8.00 & -7.00 & 12 & 6 & 2.0 \\
\hline P3 & 13 & -5.25 & -4.50 & 18 & 10 & 2.6 \\
\hline P4 & 15 & -4.75 & -5.50 & 30 & 18 & 1.6 \\
\hline P5 & 35 & -5.50 & -4.50 & 18 & 6 & 1.6 \\
\hline P6 & 15 & -5.00 & -5.00 & 16 & 4 & 1.6 \\
\hline P7 & 16 & -6.25 & -7.25 & 45 & 50 & 2.1 \\
\hline P8 & 40 & -0.75 & -0.75 & 20 & 14 & 1.6 \\
\hline P9 & 16 & -0.25 & -0.25 & 25 & 8 & 2.0 \\
\hline PIO & 32 & -3.00 & -3.00 & 30 & 10 & 1.7 \\
\hline PII & 23 & -5.25 & -4.25 & 30 & 18 & 2.3 \\
\hline
\end{tabular}

Abbreviations: APCT, alternate prism and cover test; LE, left eye; PD-bi, prism D base in; RE, right eye. 
Table 2 Demographics of individuals in the control group

\begin{tabular}{|c|c|c|c|c|c|c|}
\hline \multirow[t]{2}{*}{ ID } & \multirow[t]{2}{*}{ Age (years) } & \multicolumn{2}{|c|}{ Spherical equivalent (D) } & \multicolumn{2}{|c|}{ APCT (PD-bi) } & \multirow{2}{*}{$\begin{array}{l}\text { Stereoacuity } \\
\text { (log arcsec) }\end{array}$} \\
\hline & & RE & LE & Near & Distance & \\
\hline$\overline{\text { SI }}$ & 30 & -5.50 & -5.50 & 8 & 0 & 1.6 \\
\hline S2 & 33 & -5.00 & -5.00 & 18 & 0 & 1.6 \\
\hline S3 & 29 & -5.00 & -4.75 & 0 & 0 & 1.6 \\
\hline S4 & 35 & -0.50 & -0.75 & 6 & 0 & 1.6 \\
\hline S5 & 30 & -1.00 & -1.00 & 10 & 4 & 1.6 \\
\hline S6 & 23 & 0.50 & 0.00 & 0 & 0 & 1.6 \\
\hline S7 & 25 & -2.25 & -2.00 & 2 & 0 & 1.6 \\
\hline S8 & 25 & -3.25 & -3.25 & 12 & I & 1.6 \\
\hline S9 & 23 & -2.50 & -2.00 & 10 & 0 & 1.6 \\
\hline SIO & 25 & -3.50 & -4.25 & 2 & 0 & 1.6 \\
\hline SII & 22 & -4.00 & -3.50 & 0 & 0 & 1.6 \\
\hline $\mathrm{s} 12$ & 21 & -3.00 & -3.00 & 0 & 0 & 1.6 \\
\hline $\mathrm{S} 13$ & 21 & 0.75 & 0.50 & 12 & 0 & 1.6 \\
\hline $\mathrm{SI} 4$ & 27 & 0.00 & 0.00 & 10 & 0 & 1.6 \\
\hline SI5 & 30 & -3.00 & -3.00 & 25 & 0 & 1.6 \\
\hline
\end{tabular}

Abbreviations: APCT, alternate prism and cover test; LE, left eye; PD-bi, prism D base in; RE, right eye.

in the X(T) group ( $50 \mathrm{~cm}$, adjusted $R^{2}=0.12, P=0.29 ; 30 \mathrm{~cm}$, adjusted $R^{2}=0.49, P=0.01 ; 20 \mathrm{~cm}$, adjusted $R^{2}=0.38, P=0.02$; Figure 4).

The horizontal fixation disparity calculated as less than $2^{\circ}$ did not differ significantly between the $\mathrm{X}(\mathrm{T})$ and control groups at any distance $\left(50 \mathrm{~cm},-0.15^{\circ} \pm 0.16^{\circ} \mathrm{vs}-0.15^{\circ} \pm 0.21^{\circ}\right.$, $P=0.65 ; 30 \mathrm{~cm},-0.22^{\circ} \pm 0.35^{\circ}$ vs $-0.13^{\circ} \pm 0.26^{\circ}, P=0.73$; and $20 \mathrm{~cm},-0.54^{\circ} \pm 0.25^{\circ}$ vs $-0.37^{\circ} \pm 0.29^{\circ}, P=0.13$; Figure 5). In contrast, the horizontal fixation disparity was significantly greater at $20 \mathrm{~cm}$ than at 50 and $30 \mathrm{~cm}$ within each group [X(T): 20 vs $50 \mathrm{~cm}, P=0.008 ; 20$ vs $30 \mathrm{~cm}, P=0.03$; Control: 20 vs $50 \mathrm{~cm}, P=0.03 ; 20$ vs $30 \mathrm{~cm}, P=0.02$; Figure 5].

\section{Discussion}

In the present study, binocular coordination during smartphone reading with a vertical script was evaluated in youth and adult patients with $\mathrm{X}(\mathrm{T})$ and compared with individuals with normal vision. VOG shows that patients with $\mathrm{X}(\mathrm{T})$ sometimes view the smartphone screen monocularly, doing so significantly more frequently at a distance of $20 \mathrm{~cm}$ than at $50 \mathrm{~cm}$ (Figures 2 and $3 \mathrm{~A}, \mathrm{Video} \underline{\mathrm{S} 2}$ ). The reading speed is significantly slower in the $\mathrm{X}(\mathrm{T})$ group than in controls. It is significantly negatively correlated with the proportion of monocular viewing in the $\mathrm{X}(\mathrm{T})$ group at 30 and $20 \mathrm{~cm}$ (Figures 3B and 4). Our findings suggest that patients with (a)

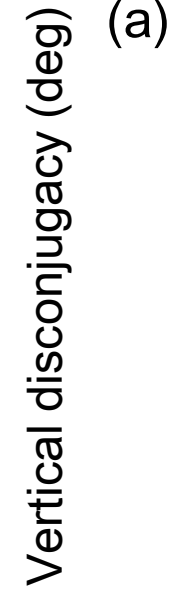

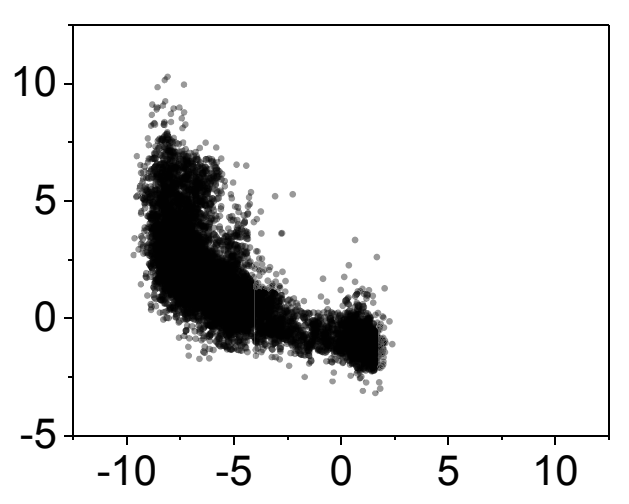

(b)

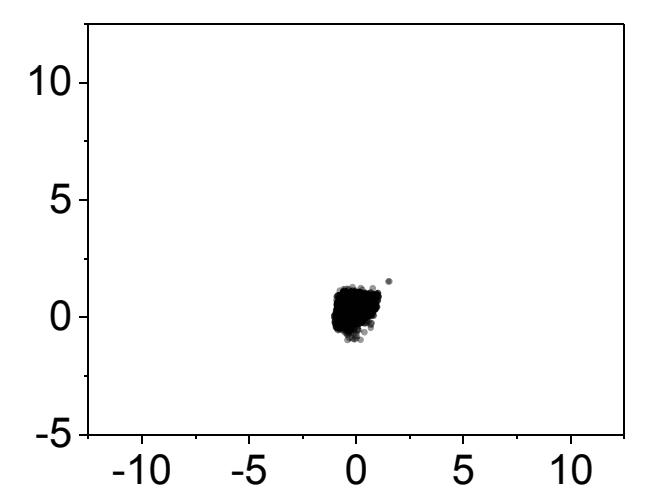

\section{Horizontal disconjugacy (deg)}

Figure 2 Gaze plot during smartphone reading.

Notes: (A) Representative data of a participant with intermittent exotropia at a viewing distance of $20 \mathrm{~cm}$. (B) Representative data of an individual with normal vision at $20 \mathrm{~cm}$. Positive values represent crossed fixations (eso- or hyperfixation disparity), whereas negative values represent uncrossed fixations (exo- or hypofixation disparity). 


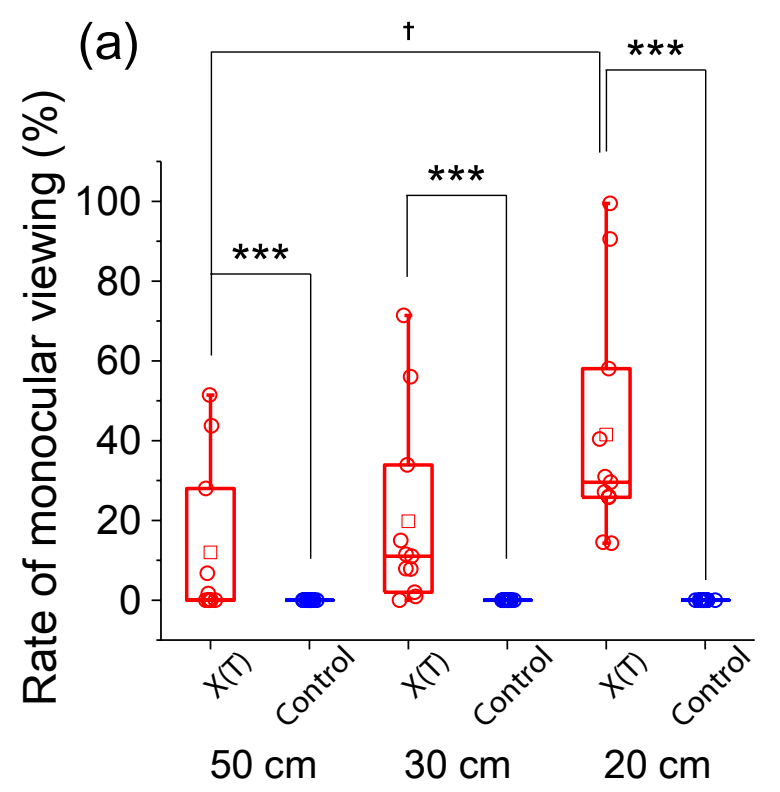

(b)

\section{Viewing distance}

Figure 3 Proportion of viewing and reading speed.

Notes: (A) Proportion of monocular viewing during smartphone reading. The blue and red box plots with dots indicate the $X(T)$ and control groups. The red and blue squares indicate the mean value in each group. ${ }^{* * *} P<0.001$, Mann-Whitney $U$ test. ${ }^{\dagger} P<0.05$, Schéffe test. (B) Reading speed during smartphone reading. ${ }^{*} P<0.05$, Mann-Whitney $U$ test. ${ }^{\dagger} P<0.05$, Schéffe test. $X(T)$, intermittent exotropia.

Abbreviation: cps, number of characters per second.

$\mathrm{X}(\mathrm{T})$ have reduced reading performance because of more frequent monocular viewing when using a smartphone at close distances.

All participants are not aware of diplopia and/or blurred vision during smartphone reading. Bababekova et a ${ }^{17}$ reported that among healthy young individuals, the viewing distance of a smartphone is closer than that of a hardcopy text. Yoshimura et $\mathrm{l}^{16}$ reported that smartphone viewing distance was significantly shorter when the user was lying down rather than sitting up. Therefore, individuals with $\mathrm{X}(\mathrm{T})$ may not be able to maintain convergence when viewing a smartphone, although they are not aware of diplopia and blurred vision because the exodeviated eye is suppressed.

The reading speed is significantly slower at $50 \mathrm{~cm}$ than at $30 \mathrm{~cm}$ in both groups (Figure 3B). In the control group, the reading speed is significantly slower at $50 \mathrm{~cm}$ than at $20 \mathrm{~cm}$ (Figure 3B), but the speed does not differ significantly at those distances in the $\mathrm{X}(\mathrm{T})$ group. As mentioned in the

Table 3 Comparison between $X(T)$ and control groups

\begin{tabular}{l|l|l|l}
\hline & $\mathbf{X}(\mathbf{T})$ & Control & P-value \\
\hline $\begin{array}{l}\text { Monocular viewing proportion (\%) } \\
\text { Reading distance of } 50 \mathrm{~cm}\end{array}$ & $11.9 \pm 19.5$ & 0 & $<0.00 \mathrm{I}$ \\
$30 \mathrm{~cm}$ & $19.7 \pm 23.8$ & 0 & $<0.00 \mathrm{I}$ \\
$20 \mathrm{~cm}$ & $41.0 \pm 29.4$ & 0 & $<0.00 \mathrm{I}$ \\
\hline Reading speed (cps) & & & 0.5 \\
$\quad$ Reading distance of $50 \mathrm{~cm}$ & $6.3 \pm 0.8$ & $7.2 \pm 1.8$ & 0.04 \\
$30 \mathrm{~cm}$ & $7.9 \pm 1.4$ & $9.3 \pm 1.7$ & 0.01 \\
$20 \mathrm{~cm}$ & $7.4 \pm 1.1$ & $9.4 \pm 2.0$ & \\
\hline Horizontal fixation disparity (degree) & & & 0.65 \\
Reading distance of $50 \mathrm{~cm}$ & $-0.15 \pm 0.16$ & $-0.15 \pm 0.21$ & 0.73 \\
$30 \mathrm{~cm}$ & $-0.22 \pm 0.35$ & $-0.13 \pm 0.26$ & 0.13 \\
$20 \mathrm{~cm}$ & $-0.54 \pm 0.25$ & $-0.37 \pm 0.29$ & \\
\hline
\end{tabular}

Notes: The values indicate mean $\pm S D$ in $X(T)$ and control groups. $X(T)$, intermittent exotropia.

Abbreviation: cps, characters per second. 
(a)

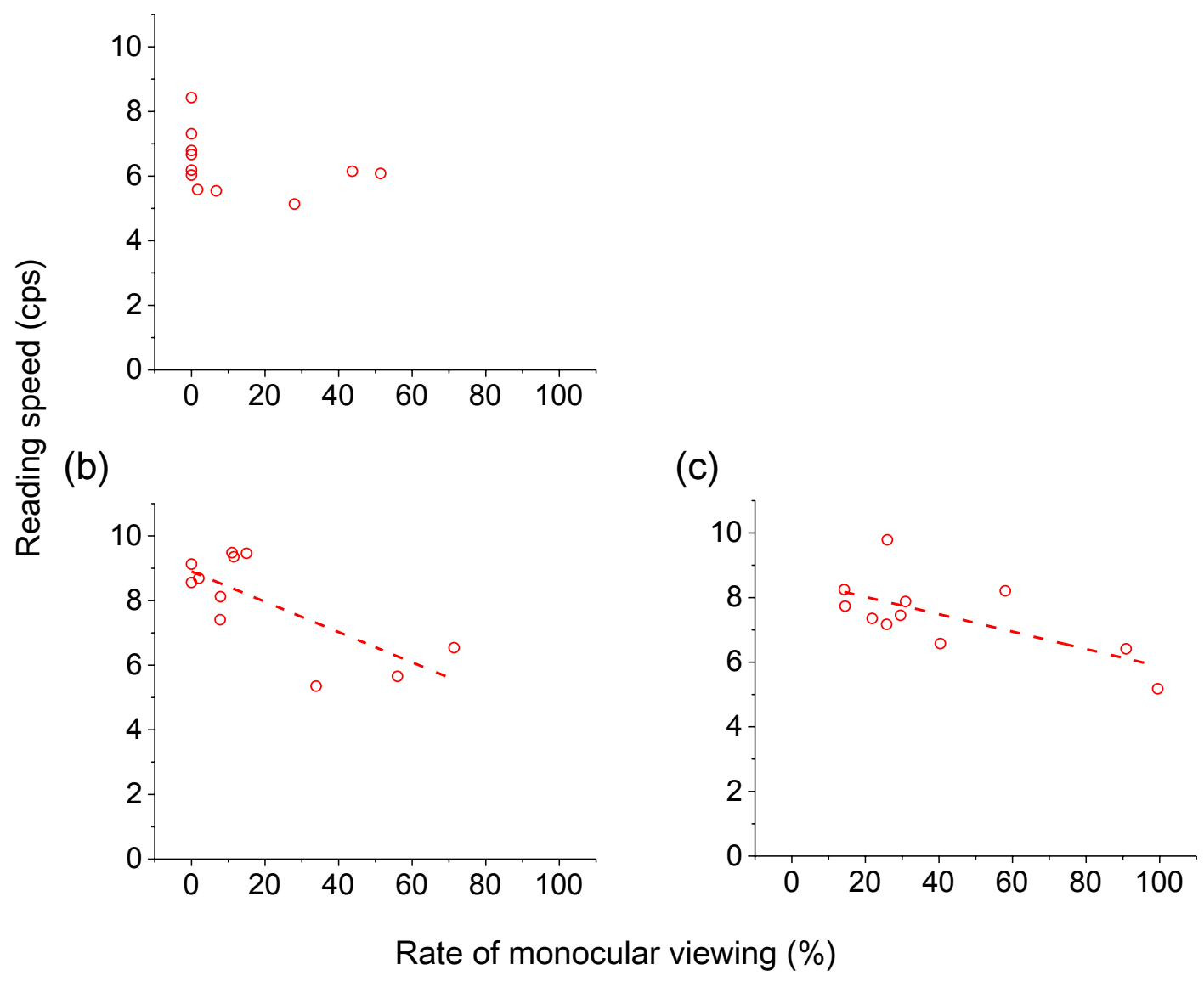

Figure 4 Relationship between reading speed and proportion of monocular viewing during smartphone reading in patients with intermittent exotropia. Notes: The red dashed lines indicate the regression line. (A) Viewing distance at $50 \mathrm{~cm}$. (B) Viewing distance at $30 \mathrm{~cm}$. Regression line: $y=-0.47 x+8.90 \mathrm{I}$. (C) Viewing distance at $20 \mathrm{~cm}$. Regression line: $y=-0.27 x+8.559$. $X(T)$, intermittent exotropia.

Abbreviation: cps, characters per second.

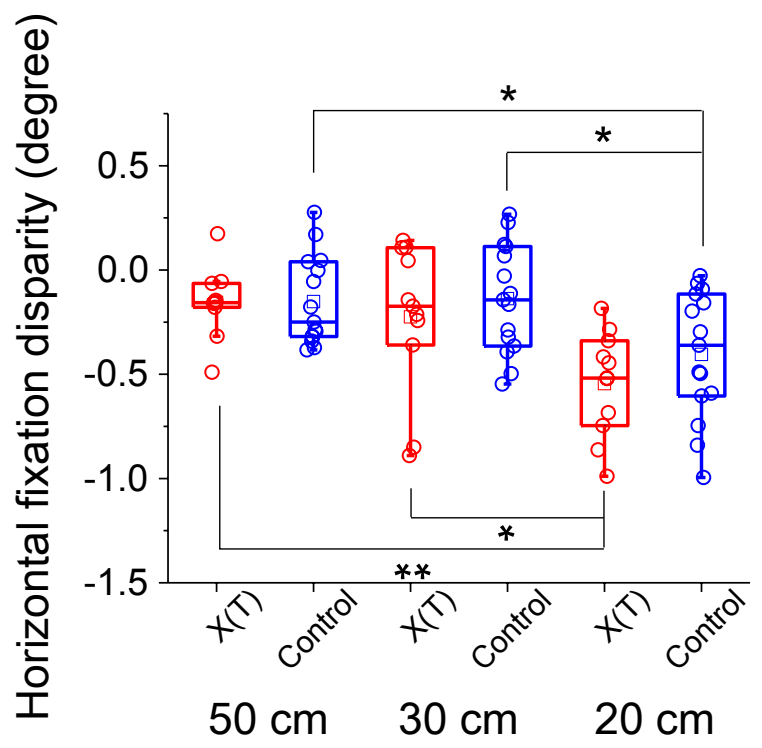

Figure 5 Horizontal fixation disparity during smartphone reading.

Notes: The blue and red box plots with dots indicate the $X(T)$ and control groups. The red and blue squares indicate mean values in each group. ${ }^{*} P<0.05, * * p<0.01$, Schéffe test.
Patients and methods section, the reading task uses a standard font size like that commonly used on smartphones. Legge and Bigelow ${ }^{21}$ and Legge et $\mathrm{a}^{22}$ demonstrated that reading speed in healthy individuals depended on font size, with slower reading when the font size was less than about $0.3^{\circ}$. Therefore, the present findings are similar to those in earlier evidence.

The slower reading speed in the $\mathrm{X}(\mathrm{T})$ group at 20 $\mathrm{cm}$ and $30 \mathrm{~cm}$ is significantly negatively correlated with the proportion of monocular viewing in the $\mathrm{X}(\mathrm{T})$ group (Figure 4). This suggests that monocular viewing in this group adversely affects reading performance and confirms that the speed does not differ significantly between $50 \mathrm{~cm}$ and $20 \mathrm{~cm}$ distances in the $\mathrm{X}(\mathrm{T})$ group. Studying healthy adults, Johansson et $\mathrm{a}^{23}$ reported that fixation duration and length of regressive saccades in monocular viewing were significantly prolonged compared with those in binocular viewing, although the reading speed did not differ significantly. The subjects were occluded in one eye during the reading task 
in their study. Conversely, the participants with $\mathrm{X}(\mathrm{T})$ in our study undergo the reading task in binocular condition and have repeated fusion breaks and refusion during smartphone reading (Video $\underline{\mathrm{S} 2}$ ). Therefore, we suggest that the proportion of monocular viewing indirectly reflects the incidence of fusion breaks and refusion.

The horizontal fixation disparity changes in the exo direction as viewing distance is shortened, although there is no significant difference between the two groups (Figure 5). We suggest that the horizontal fixation disparity does not significantly differ between the groups, because it is calculated only for the interval when disparity in binocular coordination is less than $2^{\circ}$. The fixation disparity is dependent on viewing distance, ${ }^{24}$ and disparity in the exo direction is one of the indicators of visual fatigue. ${ }^{25}$

In this study, VOG shows that participants with $\mathrm{X}(\mathrm{T})$ sometimes view the smartphone screen monocularly, and the slower reading speed at $20 \mathrm{~cm}$ and $30 \mathrm{~cm}$ significantly correlates negatively with the proportion of monocular viewing in the $\mathrm{X}(\mathrm{T})$ group. However, the authors consider that these findings do not apply to all patients with $\mathrm{X}(\mathrm{T})$ because individuals with divergence excess type of $\mathrm{X}(\mathrm{T})$ were not enrolled in the present study, and their exodeviation is greater at a larger distance than at near distance. ${ }^{11}$ Another limitation of this study is that the effects of the type of display, font size, and script direction were not evaluated. Thus, the authors consider that it is necessary to clarify whether monocular viewing is a phenomenon unique to smartphone reading with a vertical script or if it also occurs in smartphone reading with a horizontal script or with other devices, such as hard copy text or tablets. In future studies, we intend to investigate the effects of the type of display and font size in maintaining binocular coordination, comparing reading electronic devices with reading hard copy text.

\section{Conclusion}

A significant increase in the proportion of monocular viewing in the $\mathrm{X}(\mathrm{T})$ group and in fixation disparity in normal subjects when viewing a smartphone at a distance of $20 \mathrm{~cm}$ suggests that an adequate viewing distance should be advised to maintain binocular coordination in individuals with $\mathrm{X}(\mathrm{T})$ or to reduce visual fatigue in individuals with normal vision.

\section{Acknowledgments}

The study was supported by a grant from the Translational Research Network Program from the Ministry of Education, Culture, Sports, Science and Technology, Japan, B03, Development of a STS retinal prosthesis for walking (to Takashi Fujikado); the Asian CORE Program, Japan Society for the
Promotion of Science (JSPS), Advanced Nano Photonics Research and Education Center in Asia (to Takashi Fujikado); the JSPS Core-to-Core Program, A, Advanced Research Networks (to Takashi Fujikado); The Ministry of Education, Culture, Sports, Science and Technology Japan (MEXT) Grant-in-Aid for Scientific Research (B), J16H05487 (to Takashi Fujikado); and the Research Fellowship for Young Scientists, JSPS, 17J01295 (to Masakazu Hirota).

\section{Author contributions}

Substantial contributions of the following are acknowledged:

1. Conception and design: Masakazu Hirota and Takashi Fujikado.

2. Acquisition of data: Masakazu Hirota.

3. Analysis and interpretation of data: Masakazu Hirota, Hiroyuki Kanda, Takao Endo, Takeshi Morimoto, Tomomitsu Miyoshi, and Takashi Fujikado.

4. Drafting the article or revising it critically for important intellectual content: Masakazu Hirota, Hiroyuki Kanda, Takao Endo, Takeshi Morimoto, Tomomitsu Miyoshi, and Takashi Fujikado.

5. Final approval of the version to be published: Masakazu Hirota, Hiroyuki Kanda, Takao Endo, Takeshi Morimoto, Tomomitsu Miyoshi, and Takashi Fujikado.

6. Agreement to be accountable for all aspects of the work in ensuring that questions related to the accuracy or integrity of any part of the work are appropriately investigated and resolved: Masakazu Hirota, Hiroyuki Kanda, Takao Endo, Takeshi Morimoto, Tomomitsu Miyoshi, Takashi Fujikado.

\section{Disclosure}

The authors report no conflicts of interest in this work.

\section{References}

1. International Telecommunication Union. Global ICT Developments. 2016. Available from: https://www.itu.int/en/ITU-D/Statistics/Pages/ stat/default.aspx. Accessed September 25, 2018.

2. Pew Research Center. Teens, Social Media \& Technology Overview 2015 Smartphones Facilitate Shifts in Communication Landscape for Teens. Pew Research Center; 2015.

3. Ministry of Internal Affairs and Communications in Japan. White Paper Information and Communications in Japan. Available from: http://www. soumu.go.jp/iicp/chousakenkyu/data/research/survey/telecom/2016/02_ 160825mediariyou_houkokusho.pdf. Accessed September 18, 2018.

4. Office for National Statistics [webpage on the Internet]. Internet Access Households and Individuals; 2016. Available from: https://www.ons. gov.uk/peoplepopulationandcommunity/householdcharacteristics/ homeinternetandsocialmediausage/bulletins/internetaccesshouseholds andindividuals/2016. Accessed September 10, 2018.

5. Lee HS, Park SW, Heo H. Acute acquired comitant esotropia related to excessive Smartphone use. BMC Ophthalmol. 2016;16:37.

6. Mohney BG, Huffaker RK. Common forms of childhood exotropia. Ophthalmology. 2003;110(11):2093-2096. 
7. Matsuo T, Matsuo C. The prevalence of strabismus and amblyopia in Japanese elementary school children. Ophthalmic Epidemiol. 2005; 12(1):31-36.

8. Chia A, Roy L, Seenyen L. Comitant horizontal strabismus: an Asian perspective. Br J Ophthalmol. 2007;91(10):1337-1340.

9. Cooper J, Duckman R. Convergence insufficiency: incidence, diagnosis, and treatment. J Am Optom Assoc. 1978;49(6):673-680.

10. Cooper J, Jamal N. Convergence insufficiency-a major review. Optometry. 2012;83(4):137-158.

11. Hatt SR, Gnanaraj L. Interventions for intermittent exotropia. Cochrane Database Syst Rev. 2013;(5):CD003737.

12. Quaia C, Optican LM. Three-Dimensional Rotations of the Eye. In: Levin L, Nilsson S, Hoeve J, editors. Adler's Physiology of the Eye. 11th ed. Philadelphia: Elsevier/Saunders; 2001. Available from: http:// citeseerx.ist.psu.edu/viewdoc/download?doi=10.1.1.496.2053\&rep=re p1\&type=pdf. Accessed September 18, 2018.

13. Shimojyo H, Kitaguchi Y, Asonuma S, Matsushita K, Fujikado T. Age-related changes of phoria myopia in patients with intermittent exotropia. Jpn J Ophthalmol. 2009;53(1):12-17.

14. Kawamorita T, Uozato H. Natural Pupil Size and Ocular Aberration under Binocular and Monocular Conditions. J Comput Sci Syst Biol. 2014;7(1):15-19.

15. Katoh A, Hatanaka T, Takeuchi E, Uchida M, Natsume H. Calibration of infrared video-oculography by using bioadhesive phosphorescent particles for accurate measurement of vestibulo-ocular reflex in mice. J Adv Sci. 2015;27(3+4):11-16.

16. Yoshimura M, Kitazawa M, Maeda Y, Mimura M, Tsubota K, Kishimoto T. Smartphone viewing distance and sleep: an experimental study utilizing motion capture technology. Nat Sci Sleep. 2017;9:59-65.
17. Bababekova Y, Rosenfield M, Hue JE, Huang RR. Font size and viewing distance of handheld smart phones. Optom Vis Sci. 2011;88(7): 795-797.

18. Ogle KN, Prangen AD. Further considerations of fixation disparity and the binocular fusional processes. Am J Ophthalmol. 1951;34:57-72.

19. Nuthmann A, Kliegl R. An examination of binocular reading fixations based on sentence corpus data. J Vis. 2009;9(5):31.

20. Jainta S, Blythe HI, Nikolova M, Jones MO, Liversedge SP. A comparative analysis of vertical and horizontal fixation disparity in sentence reading. Vision Res. 2015;110(Pt A):118-127.

21. Legge GE, Bigelow CA. Does print size matter for reading? A review of findings from vision science and typography. J Vis. 2011;11(5):8.

22. Legge GE, Pelli DG, Rubin GS, Schleske MM. Psychophysics of reading - I. Normal vision. Vision Res. 1985;25(2):239-252.

23. Johansson J, Pansell T, Ygge J, Seimyr GÖ. Monocular and binocular reading performance in subjects with normal binocular vision. Clin Exp Optom. 2014;97(4):341-348.

24. Jaschinski W. Fixation disparity and accommodation as a function of viewing distance and prism load. Ophthalmic Physiol Opt. 1997;17(4): 324-339.

25. Jaschinski W. The proximity-fixation-disparity curve and the preferred viewing distance at a visual display as an indicator of near vision fatigue. Optom Vis Sci. 2002;79(3):158-169. 


\section{Supplementary materials}

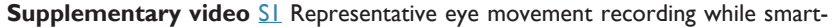
phone reading in a normal subject.

Notes: Normal subjects can read the sentences combined with small saccades and fixation. The filled red circle indicates the point in which the fixating point of both eyes is averaged. The size of the red circle represents the retention time.
Supplementary video $\underline{\mathrm{S}} \underline{\mathrm{R}}$ Representative movement recording while smartphone reading in a patient with $X(T)$.

Notes: The upper movie shows the gaze position and the lower movie shows the anterior ocular segment in the patient with $X(T)$. Patients with $X(T)$ sometimes viewed the smartphone screen monocularly. The filled red circle indicates the point in which the fixating point of both eyes is averaged. The size of the red circle represents the retention time. $X(T)$ indicates intermittent exotropia.

\section{Publish your work in this journal}

Clinical Ophthalmology is an international, peer-reviewed journal covering all subspecialties within ophthalmology. Key topics include: Optometry; Visual science; Pharmacology and drug therapy in eye diseases; Basic Sciences; Primary and Secondary eye care; Patient Safety and Quality of Care Improvements. This journal is indexed on
PubMed Central and CAS, and is the official journal of The Society of Clinical Ophthalmology (SCO). The manuscript management system is completely online and includes a very quick and fair peer-review system, which is all easy to use. Visit http://www.dovepress.com/ testimonials.php to read real quotes from published authors. 